\title{
ALIRAN BASRAH; SEJARAH LAHIR, TOKOH DAN KARAKTERISTIKNYA
}

\author{
RAHMAP \\ Penulis adalah dosen tetap Jurusan PBA Fakultas Tarbiyah IAIN Pontianak Kal-Bar sejak \\ tahun 2008 dengan mata kuliah bahasa Arab. Setelah merampungkan studi S-3 di PPs UIN \\ Alauddin dan kembali aktif dia diberikan tugas tambahan sebagai Kajur PAI S-2 \\ Pascasarjana IAIN Pontianak
}

\begin{abstract}
ABSTRAK
Since Basra was a trading port for Iraq in the Arab Gulf, foreign influences that affected the progress in the field of trade and investment. Here in this port, encounters occurred between Arabs, Persians and Indians as well as between the religions of Christianity, Judaism, Majus and Islam. The closeness between Basra and the Gandisabur school in Persia that studied the Persian, Greek, and Indian culture has generated a mix of culture as a whole. During the period of Umar ibn Abdul Aziz, translation works on medical books were carried out by Masir Haubah. The same thing was also undertaken by Abdullah al-Muqaffa' who was fluent in Arabic and Persian. He translated books on the Persian literature and history into Arabic. From the son of Abdullah al-Muqaffa, Muhammad, the Arabic translation of Aristotle's science of logic Kali>lah wa Dimnah was produced. There was also a Jewish translator named Hunain Ibn Ishaq, who translated books and got rewards in the form of gold for each weight of books he translated. In Basra, there was a school of Mu'tazilah that learnt the Greek sciences. This strongly affected the school of sciences he learnt such as the science of kalam and nahwu in terms of taqsim, ta'lil, ta'wil dan qiyas.
\end{abstract}

\section{SEKILAS MENGENAI BASRAH}

Basrah adalah kota kedua terbesar di Irak yang dibangun pada awal perkembangan Islam sekitar tahun $16 \mathrm{H}$, tepatnya pada masa pemerintahan khalifah Umar bin al-Khattab. Ketika 'Utbah bin Gazwan pergi ke selatan Irak, ia bertemu dengan Suwaid bin Qutbah al-Dzuhli beserta kekuatan dari bani Bakr bin Wail dan bani Tamim yang sedang bergerak mendekati pasukan yang berdekatan dengan mereka di Persi. 'Utbahpun bergabung dengan tentara Suwaid lalu tingal bersama di tenda-tenda. Akan tetapi 'Utbah berpendapat bahwa pasukannya membutuhkan tempat tinggal yang bisa dipakai nanti jika kembali dari berperang dan melindungi mereka dari dinginnya hujan. Utbah mengirim surat pada khalifah untuk meminta ijin tentang gagasannya tersebut. Khalifah membalas dan memerintahkan supaya Utbah mengumpulkan pasukannya di satu tempat dekat dengan air dan terjaga, jangan ada gunung dan sungai yang memisahkannya, dan meminta agar dituliskan sifat tempat yang dimaksud. Maka 'Utbah menulis kepada khalifah bahwa ia menemukan tempat yang tanahnya berkerikil, yang berada di ujung pedalaman, terdapat air dan buluh di dalamnya. Khalifah kemudian menyebutnya Basrah, dekat dengan sumber 
air, tempat perlindungan, dan juga tempat mencari kayu bakar. Beliau menyepakatinya untuk dijadikan tempat pemukiman tentara. ${ }^{1}$

Sebagaimana diketahui bahwa $\mathrm{Nahwu}^{2}$ sebagi suatu ilmu, tumbuh dan berkembang di tangan para ulama Basrah. Sebenarnya Kufah telah melakukan hal yang sama, namun bagaimanapun juga, Basrah-lah sebagai pionir dan yang paling awal dalam hal ini. Terciptanya kondisi Basrah seperti ini tidak lepas dari beberapa hal berikut:

a. Basrah terletak pada jarak tiga ratus mil ke arah tenggara dari kota Bagdad, terdapat sungai Tigris dan Euphrates yang mengalir dan bermuara di laut. Kondisi strategis seperti ini tentunya akan berpengaruh kuat terhadap pembentukan personalitas penduduk yang membuatnya berfikir matang dan terkenal.

b. Letak kota Basrah yang berada di pinggir pedalaman, bahasanya yang fasih dan murni tetap terjaga, terbebas dari cacat $l a h n^{3}$ dan kata-kata asing.

c. Di Basrah terdapat para ilmuwan yang sering melakukan perjalanan ke pedalaman. Namun adakalanya juga membawa orang Badui ke kota Basrah. Di tengah perjalanan, biasanya bertemu dengan orang Arab asli dan melakukan

\footnotetext{
${ }^{1}$ Utbah menamakan kota yang dibangunnya (Basrah) sesuai nama bahan yang digunakan membangun kota tersebut yaitu al-Basrah artinya sejenis batu putih. Lihat Dewan Redaksi, Ensiklopedi Islam, Jilid I (Jakarta: PT Ikhtiar Baru Van Hove, 1994), h. 243

${ }^{2} \mathrm{Nahwu}$ adalah ilmu yang membahas bidang kajian mengenai aturan struktur kata dalam hubungannya dengan kata lain atau unsure-unsur lain sebagai suatu satuan ujaran. Lihat Imam Saiful Mu'minin, Kamus Ilmu Nahwu dan Sharaf, Cet. II (Jakarta: Amzah, 2009), h. 252

${ }^{3}$ Artinya ialah ungkapan yang menyalahi kaidah dan uslub bahasa Arab yang sudah sering terjadi pada masa Nabi sebagaimana dikemukakan oleh Abu alTayyib. Selengkapnya lihat al-Thohthowiy, op., cit. h. 9

${ }^{3}$ Abd al-Salam Harun, Kitab Sibawaih, Juz I (Dar alJail, t.t)
}

pembicaraan dari sumber bahasa yang asli.

d. Orang yang terkenal melakukan perjalanan ke pedalaman untuk melakukan survey bahasa dan mengumpulkannya adalah Khalil bin Ahmad, Yunus bin Habib, Nadhar bin Syamil, dan Abu Zaid al-Anshari.

Hal ini tampak jelas perkataan Khalil ketika ditanyai oleh al-Kisai tentang sumber-sumber ilmunya (pedalaman Hijaz, Najd dan Tihama), maka al-Kisai pun segera keluar menuju pedalaman dan menghabiskan lima belas botol tinta untuk menulis bahasa Arab selain dari yang sudah dihafalnya. Kedatangan orang-orang Badui dari pedalaman ke Basrah sungguh telah memberikan gambaran yang beraneka ragam. Dari mereka yang tinggal hanya untuk sementara kemudian kembali ke pedalaman dan adapula yang tinggal cukup lama dan baru kembali ke qabilah mereka, bahkan jika ada yang mendapatkan tempat yang nyaman di Basrah mereka tidak kembali. Banyak para siswa yang belajar bahasa menemui orang-orang Badui untuk mendengar percakapan mereka dan mengambilnya 4 .

Setelah ilmu gramatikal bahasa arab tersusun dan banyaknya ulama yang telah memperjelas ilmu tersebut, maka muncullah aliran-aliran dalam ilmu nahwu, yang disebabkan adanya khilaf di kalangan para ulama nahwu dalam menentukan posisi (mahal) kata dalam suatu kalimat. perbedaan persepsi ini tidak luput dari pengaruh daerah tempat para ulama tersebut menetap. Aliran-aliran ilmu nahwu yang dikenal ialah aliran Basrah, Kufah, Baghdad, Andalus dan Mesir. Namun, aliran yang paling terkenal dalam kitabkitab nahwu hanya dua, Basrah dan Kufah ${ }^{5}$. Oleh karena itu pemakalah hanya

${ }^{5}$ Selengkapnya mengenai aliran-aliran dalam ilmu nahwu, lihat Syauqiy Dheef, al-Madaris alNahwiyah, Cet. III (Dar al-Ma'arif Beirut, t.t), h. 1122 
membahas aliran Basrah dengan dua fokus pembahasan yaitu; latar belakang lahirnya ilmu nahwu di Basrah dan tokoh-tokoh aliran Basrah beserta karakteristik yang dimilikinya.

\section{LATAR BELAKANG LAHIRNYA ILMU NAHWU DI BASRAH}

Berdasarkan apa yang sudah dipahami selama ini tentang karakteristik dan fungsi ilmu nahwu, kiranya sudah jelas bagi bahwa nahwu tidaklah sebagaimana yang didefinisikan oleh sebagian orang, yakni "mengetahui harakat dari akhir kata serta i'rabnya"'. Ruang lingkup ilmu nahwu lebih luas dari pada sekedar membahas masalah harakat akhir suatu kata. Ilmu nahwu merupakan ilmu yang khusus berbicara tentang aturan menyusun dan merangkai ucapan. Kata-kata disusun berdasarkan pola-pola tertentu dan kaidahkaidah yang sudah ada. Demikianlah katakata itu tersusun berdampingan satu sama lain. Setiap kata memiliki harakat dan posisi yang berbeda-beda sesuai dengan aturan umum yang berlaku. Nahwu merupakan ilmu yang mengatur kata-kata, mempelajari tentang pengaturan kalimat dalam berbagai macam dan bentuknya. Mempelajari tentang elemen-elemen kalimat baik dari sisi kedudukannya, fungsinya, kaitannya, i'rabnya, dan hal-hal lain yang termasuk dalam aturan-aturan nahwu.

Seperti halnya bahasa-bahasa dunia lainnya, bahasa $\mathrm{Arab}^{7}$ mempunyai kaidahkaidah tersendiri di dalam mengungkapkan atau menuliskan sesuatu hal, baik berupa komunikasi maupun informasi. Lalu, bagaimana sebenarnya awal mula terbentuknya kaidah-kaidah ini, dan mengapa dikatakan dengan istilah nahwu?

\footnotetext{
${ }^{6}$ Mushtafa Galayaini. Jami'al-Durus al-'Arabiyah, (Juz I, Maktabah 'Ashriyah. 1994). h. 8

${ }^{7}$ Bahasa Arab ialah bahasa orang arab dan Islam,... Selengkapnya lihat Azhar Arsyad, Madkhal ila Thuruq Ta'lim al-Lughah al-Arabiyah, , perc. AlAhkam Makassar, (cet. I, 1998), h. 3
}

Pada jaman jahiliyah, kebiasaan orangorang Arab ketika berucap atau berkomunikasi dengan orang lain, mereka melakukannya dengan karakternya masingmasing.

Lafazh-lafazh yang muncul terbentuk berdasarkan peraturan yang telah ditetapkan, di mana para junior belajar kepada senior, para anak belajar bahasa kepada orang tuanya dan seterusnya. Namun ketika Islam datang dan menyebar ke negeri Persia dan Romawi, terjadilah pernikahan orang Arab dengan orang non Arab, serta terjadi pula perdagangan dan pendidikan. Hal ini menjadikan bahasa Arab bercampur baur dengan bahasa non Arab. Orang yang fasih bahasanya menjadi jelek dan banyak terjadi salah ucap, sehingga keindahan bahasa Arab menjadi rusak bahkan hilang. ${ }^{8}$

Jadi kondisi inilah yang mendorong dilakukannya penyusunan kaidah-kaidah yang disimpulkan dari ucapan orang Arab yang fasih lalu dijadikan rujukan dalam memberi harakat huruf akhir setiap kata. Muncullah ilmu yang pertama kali disusun untuk menghindarkan bahasa Arab dari kerusakan, yang disebut dengan ilmu Nahwu. Adapun orang yang pertama kali menyusun ilimu tentang kaidah-kaidah bahasa Arab adalah Abu al-Aswad al-Duali dari Bani Kinanah atas dasar perintah Khalifah Ali Bin Abi Thalib.

Terdapat suatu kisah yang dinukil dari Abu al-Aswad al-Duali, bahwasanya ketika sedang berjalan-jalan dengan putrinya pada malam hari, lalu sang anak menghadapkan wajahnya ke langit dan menyaksikan betapa indahnya benda-benda yang dilihatnya berupa bintang-bintang. Kemudian mengungkapkan perasaan مَا أَحْسَنَ السَّمَاءِ 'apakah yang paling indah di langit?' tanpa menyadari bahwa dengan mengkasrah huruf hamzah berarti menunjukkan kalimat tanya. Sehingga sang ayah berkata sebagai

\footnotetext{
${ }^{8}$ Syauqy Dheef, Op. Cit., h. 25
} 


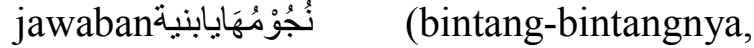
anakku). Namun sang anak menyanggah dengan mengatakan Saya hanya ingin mengungkapkan kekaguman". Maka sang ayah mengatakan; kalau begitu ucapkanlah, مَا احسنَ السماء (betapa indahnya langit). ${ }^{9}$

Pada pagi hari, Abu alAswad al-Duali menghadap Ali bin Abi Tholib sebagai khalifah dan melaporkan kepadanya percakapan yang terjadi dengan putrinya, intinya sesuatu yang tidak dipahaminya. Imam Ali berkata; Ini adalah akibat bercampurnya bahasa Ajam (non Arab) dan Bahasa Arab. Khalifah memerintahkan Abu al-Aswad al-Duali untuk membuat aturan bahasa. Abul Aswad lalu membeli sehelai kertas dan setelah beberapa hari beliau menulis di atasnya pembagian kalimat yang terdiri dari tiga bagian, yaitu isim, fi'l dan harf serta ditambah ta'ajjub kemudian tulisan itu disodorkan pada Imam Ali. Lalu Imam Ali berkata: Inha nahwa haadza (buatkan contoh seperti ini), karena itulah ilmu ini dinamakan "Ilmu Nahwu"10.

Dikisahkan pula bahwa ketika Abu al-Aswad al-Duali melewati seseorang yang sedang membaca al-Qur'an, mendengar qari' membaca surat At- Taubah ayat 3 dengan bacaan;

$$
\text { ان الله بريئ من المشركين ورسوله } 11
$$

Dengan mengkasrah huruf la $>m$ pada kata rasu $>$ lihi, artinya "Sesungguhnya Allah berlepas diri dari orang-orang musyrik dan rasulnya.." hal ini jelas sangat merusak makna ayat tersebut dan menyesatkan. Seharusnya huruf tersebut dibaca fathah, artinya "Sesungguhnya Allah dan Rasul-Nya berlepas diri dari orangorang musyrik". Karena mendengar perkataan ini, Abu al-Aswad al-Duali menjadi khawatir kalau keindahan bahasa Arab menjadi rusak dan keasliannya menjadi hilang, apalagi hal tersebut terjadi

\footnotetext{
${ }^{9}$ al-Thahthowiy, Nasyah al-Lughah,(t. t), h. 9

${ }^{10}$ Ibid, h. 9

${ }^{11}$ QS., al-Taubah: 3
}

di awal mula daulah islamiyah. Hal ini disadari oleh khalifah Ali bin Abi Thalib, sehingga ia memperbaiki keadaan ini dengan membuat pembagian kata, bab inna dan saudaranya, bentuk id\}a>fah (penyandaran), kalimat ta'ajjub (kekaguman), kata tanya dan selainnya, kemudian Ali bin Abi Thalib berkata kepada Abu al-Aswad al-Duali, أنْحُ هَذَا النَّْْوَ"Ikutilah jalan ini”. Dari kalimat inilah, ilmu tentang kaidah bahasa Arab disebut dengan ilmu nahwu. (Arti nahwu secara bahasa adalah arah). Lalu hal ini mendorong Abul Aswad berfikir untuk meletakkan kaidah-kaidah nahwu ${ }^{12}$.

Jelaslah bahwa yang pertama kali meletakkan kaidah nahwu adalah Abu al-Aswad al-Duali, baik itu dengan petunjuk dari Ali bin Abu Thalib atau dicetuskan sendiri. Kemudian muncullah gerakan untuk mengarang kaidah nahwu berturut-turut sesudah itu. Dimulainya gerakan ini dengan pengaruh sebagian masalah-masalah nahwu sekitar ayat-ayat Al Qur'an dan bait-bait syair, dan dikatakan bahwa Isa bin Tsaqafi yang wafat tahun 149 $\mathrm{H}$ telah mengumpulkan masalah-masalah itu dalam dua kitab yang ia berinama al$J a>m i$ ' dan al-Ikma>l, akan tetapi kedua kitab ini sedikitpun tidak sampai kepada kita. $^{13}$

Kemudian datang sesudah itu alKhalil bin Ahmad al-Farahidi al-Busairi yang wafat pada tahun $175 \mathrm{H}$. Ia mempunyai teori yang detail dalam ilmu nahwu serta ilmu yang luas. Ia meneliti dan menyimpulkan lebih luas nash-nash dan dalil-dalil penguat yang lebih banyak dari para pendahulunya. Ia banyak meletakkan kaidah pokok ilmu nahwu sampai mendekati uslub-uslub yang kita gunakan dalam membaca bahasa arab saat ini. Akan tetapi ia tidak meninggalkan satu karangan pun tentang ilmu nahwu. Beliau hanya memberitahukan ringkasan pemikirannya

\footnotetext{
${ }^{12}$ Mazin al-Mubarak, al-Nahw al-Arabiy; al-'Illah al-Nahwiyyah, Jilid III, (Dar al-Fikr, 1981), h. 44 ${ }^{13}$ Ibid
} 
kepada muridnya yang masyhur bernama Sibawaih yang mengumpulkan ilmu gurunya dalam ringkasan-ringkasan pendapatnya dan pendapat-pendapat ahli yang hidup semasanya. Beliau susun pendapat-pendapat tentang ilmu nahwu itu semuanya, dan ia kumpulkan dalam kitabnya yang bernilai tinggi berjudul alKita $>b$. Buku tersebut mendapatkan pengakuan dan kepercayaan para ulama. Kitab itu tersebar ke seluruh dunia hingga saat ini dan dimiliki dunia pendidikan bahasa Arab. Kalangan pencinta pembelajaran bahasa Arab senantiasa menyibukkan diri mengkaji kitab Sibawaih sehingga ada ungkapan; "Barangsiapa yang belum membaca kitab Sibawaih maka tidaklah pantas menjadi ahli nahwu" ${ }^{14}$.

Perlu diketahui bahwa yang menjadi landasan dari pelajaran-pelajaran ilmu nahwu adalah al-Quran, hadits Rasulullah, syair yang dipercayai kebenarannya, ucapan-ucapan bangsa Arab dalam perjalanan menuntut ilmu bahasa Arab. Para ulama memikul beban dalam usaha dengan jihad yang lama. Tidak semua kabilah-kabilah ${ }^{15}$ bangsa Arab dapat

\footnotetext{
${ }^{14}$ ibid

${ }^{15}$ Adalah kabilah Qois, Tamim, Asad, Hudzail, sebagian kabilah Kinanah dan sebagian kabilah Thoi, termasuk dari kabilah-kabilah yang pantas dan dipercaya untuk diambil ilmu bahasa Arabnya. Hal ini disebabkan jauhnya mereka dari tempat-tempat kesalahan pengucapan bahasa Arab. Oleh karena itu ilmu bahasa Arab mereka diambil. Imam syafii sendiri sebagai ahli bahasa Arab pergi ke tempat Bani Hudzail dengan tujuan untuk belajar. Bani Hudzail adalah kabilah yang paling fasih dalam berbahasa Arab. Beliau tinggal di tempat Bani Hudzail selama 17 tahun. Di tempat ini beliau banyak menghafal sya'ir-sya'ir, ia memahami sastra Arab secara mendalam dan berita-berita tentang peristiwa yang dialami oleh orang-orang Arab. Adapun kabilah Himyar, Lahm, Judzam, dan Kudho'ah, Ghassan, Iyad dan Tsaqif bukanlah kabilah yang pantas untuk diambil ilmu bahasa Arabnya disebabkan mereka tinggal berdampingan dengan orang-orang bukan bangsa Arab. Tampak dalam lisan-lisannya kesalahan pengucapan bahasa Arab. Oleh karena itu para ulama menjauhinya dan
}

diambil bahasanya. Hal ini disebabkan dekatnya mereka dengan peradaban dan bercampurnya dengan orang bukan bangsa Arab.

Sebagai pusat pengembangan ilmu pengetahuan, di Basrah terdapat berbagai macam majelis di dalam mesjid Basrah, di antaranya majelis kajian tafsir, ilmu kalam, bahasa dan lain-lain. Para imamnya adalah penduduk Basrah sendiri yang berbangsa Arab, Persia dan India dan sebagian lagi orang-orang Badui yang datang dari pedalaman. Di antara majelis-majelis yang ada adalah sebagai berikut:

1. Majelis Himad bin Sulmah. Sibawaih ikut bergabung dalam majelis ini. 2. Majelis Musa bin Siyar al-Aswari. Jahizd berkomentar tentangnya: "Ini merupakan keajaiban. Dia sangat fasih berbahasa Persia sama halnya dengan bahasa Arabnya. Dia duduk di majelisnya yang terkenal itu, sementara di sebelah kanannya orang Arab dan di sebelah kirinya orang Persi. Dia pun mulai membacakan al-Qur'an dan menafsirkannya dengan orang Arab menggunakan bahasa Arab dan berpaling ke orang-orang Persi dan manfsirkan ayat al-Qur'an dengan bahasa Persia".

3. Majelis Abu Umar bin al-Ila. Dia megajar qira'ah, bahasa, dan nahwu. Murid-muridnya berdesak-desakan di dalam majlisnya. Suatu ketika, Hasan alBashri lewat dan menyaksikan betapa berjejalnya murid-murid yang mengikuti majelis tersebut maka ia pun berkata: "la $>$ ila $>h a$ illalla $>h$, hampir para ulama menjadi tuhan-tuhanan, setiap kemualian tidak dibentengi dengan ilmu maka kehinaanlah yang berkuasa".

4. Di antara majelis-majelis Basrah yang paling terkenal adalah majelis Khalil bin Ahmad al-Farahidi. Majlis ini diikuti oleh para murid yang kemudian menjadi pakar bahasa dan nahwu, seperti

tidak mengambil ilmu bahasa Arab dari mereka. Lihat ibid 
Sibawaih, al-Nadhar bin Syamil, Ali bin Hamzah al-Kisai, Abi Muhammad alYazidi, al-Ashmai dan yang lainnya.

5. Majelis Yunus bin Habib yang dipenuhi pula murid-muird. Di antara para pemimpin majelis ini yang terkenal adalah Abu Ubaidah, al-Ashmai, Abu Zaid al-Anshari, Abu Muhammad alYazidi, Qatrab, Sibawaih, Abu Umar alJurmi, al-Kisai, al-Farra', Khalf Ahmar dan Ibnu Salam al-Jum'i. Halaqah Yunus dimulai pada masa Khalil dan mencapai kesempurnaan setelah wafatnya. Banyak tergabung para tokoh ke dalam majelis Yunus tersebut. Tentang majelis Yunus ini, Marwan bin Abi Hafsah berkata:"Saya belum pernah melihat halaqah yang paling mulia kecuali halaqah-nya Yunus". ${ }^{16}$

Pada awal perkembangannya, nahwu masih merupakan ilmu dengan lingkup yang kecil. Abu al-Aswad menemukannya dan kemudian dikuatkan oleh Imam Ali ra. Ilmu ini mendapat iklim yang bagus untuk berkembang di Basrah sesuai dengan keadaan Basrah waktu itu. Ilmu nahw sangat diperlukan di Basrah karena sangat banyak kesalahan bahasa di sana. Kaum muslim non Arab di Basrah sangat membutuhkan ilmu nahwu untuk memperbaiki bahasa, menghilangkan pengaruh bahasa asing, mendalami agama Islam, dan meningkatkan kedudukan mereka di kalangan orang Arab. Setelah $\mathrm{Abu}$ al-Aswad membangun sistematika ilmu nahw, ternyata orang Arab juga membutuhkannya dalam berbahasa. Setelah masa Abu al-Aswad, perbedaan mulai timbul di antara para muridnya, ${ }^{17}$ seperti 'Abdurrahman bin Hurmuz, Maimun alAqran, 'Anbasah al-Fil, Yahya bin Ya'mur, Nasr bin 'Asim, dan juga para murid berikutnya, seperti 'Isa bin 'Umar, Abu 'Amr bin al-'Ala, dan Yunus bin Habib. Dalam konteks perkembangan ilmu nahwu, maka ada lima tahap yang penting diketahui, yaitu:

\section{Tahap penggunaan contoh dan dalil}

Cara ini dipakai agar pendapat yang diambil benar dan sesuai dengan perkataan orang Arab. Abu al-Aswad memakai cara ini ketika Bani Qusyair mempertanyakan masuknya ke dalam kelompok Syiah. Kemudian Abu al-Aswad mengucapkan sebuah syair yang berbunyi

غيا فإن يك حبهم رشدا ولست بمخطئ إن كان Syair ini adalah bukti bahwa Abu alAswad tidak ragu-ragu. Pendapat Abu alAswad terkait dengan hak untuk berbeda pendapat. Dia menggunakan ayat al-Qur'an sebagai dalil, yaitu QS.34:24. ${ }^{18}$

\section{Penggunaan pendapat ulama terdahulu.}

Hal ini misalnya yang terjadi pada 'Abdullah bin Abi Ishaq yang membaca: .قل هو الله أحدّ الله الصمد. Kemudian dia mendengar Nasr bin 'Asim membacanya dengan cara: قل هو الله أحدُ الله الصمد, karena bertemunya dua tanwin. 'Abdullah mengatakan kepada Nasr bahwa 'Urwah membaca ayat tersebut dengan tanwin, tetapi Nasr mengatakan bahwa bacaan 'Urwah tidak baik. Maka 'Abdullah membaca ayat tersebut tanpa tanwin seperti yang dikatakan oleh Nasr.

\section{Perbedaan pendapat}

Perbedaan pendapat ini terkait dengan prinsip-prinsip yang dirumuskan sendiri oleh para ahli nahw. Sebagai contoh adalah 'Abdurrahman bin Hurmuz yang membaca ayat dengan bacaan:

$$
\text { أو يأتيهم العذاب قُبُلًا (الكهف } 55 \text { : }
$$

Hal ini berbeda dengan 'Isa bin 'Umar yang membaca:

$$
\text { أو يأتيهم العذاب قِبَلا .(الكهف } 55 \text { : }
$$

\footnotetext{
${ }^{16}$ Dewan Redaksi Inseklopedia, Op. Cit.

${ }^{17}$ Syauqiy Dheef, op; cit, h. 12
}

${ }^{18} \mathrm{QS}$, Saba. 24 
Abdullah bin Abu Ishaq juga membaca beberapa ayat dengan cara berbeda, misalnya

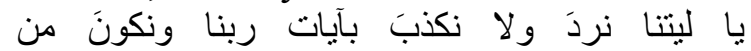

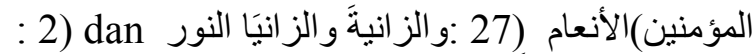

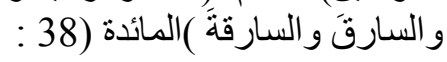

\section{Pemeriksaan dan Penafsiran}

Para ahli nahw mulai memeriksa kaidah dan menafsirkan teks sesuai dengan kaidah yang mereka susun. Sebagai contoh adalah perbedaan penafsiran antara 'Isa bin 'Umar dan 'Amr bin al-'Ala. Keduanya membaca sebuah ayat dengan cara yang sama, yaitu ayat: سبأ )يا جبال أوبي معه والطيرَ: 10). Akan tetapi, keduanya berbeda dalam penafsiran. Bagi 'Isa, cara pembacaan seperti di atas terkait dengan adanya nida', sedangkan $\mathrm{Abu}$ 'Amr menyatakan adanya

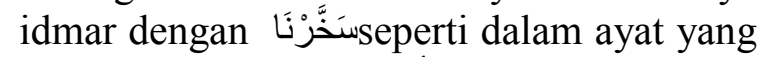

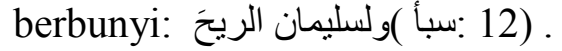

\section{Pemberlakuan Aturan Nahw}

Pemberlakuan ini dilakukan oleh para ahli nahw terkait dengan penggunaan bahasa Arab di kalangan umat Islam. Sebagai contoh adalah Abu Muslim yang menjadi pengajar khalifah Malik bin Marwan. Dia bertanya kepada seseorang mengenai ayat:(مريم ) إزاز هم أزا 83 dan ketika dipakai dalam contoh ungkapan يا فاعلٌ افعلْ : Maka orang itu menjawab dengan perkataan: يا بآل آز أز Maka Abu Muslim merasa bahwa perkataan ini tidak pernah didengarnya dari orang Arab dan memutuskan untuk tidak digunakan di kalangan umat Islam. ${ }^{19}$

\section{TOKOH-TOKOH ALIRAN BASRAH DAN KARAKTERISTIKNYA}

Berikut ini pemakalah akan menyampaikan tulisan yang menjelaskan tentang tokoh-tokoh nahwu aliran Basrah ${ }^{20}$

\footnotetext{
${ }^{19}$ ibid

${ }^{20}$ Ada beberapa literatur yang membahas tokohtokoh nahwu baik aliran Basrah maupun Kufah antara lain, baca Dewan Redaksi, Ensiklopedia
}

yang membagi dalam delapan tingkatan generasi:

\section{GENERASI PERTAMA}

1. Abul Aswad Ad-Duali

Nama lengkapnya Dzalim bin Umar bin Supyan bin Jundal bin Ya'mur bin Halis bin Nufatsah bin 'Uda ibn Du'al bin Abdu Manah bin Kinanah, dikatakan juga bernama Utsman. Dia seorang penduduk Basrah dan memiliki kekuatan ingatan. Abul Aswad termasuk orang yang fasih bacaannya. Dia belajar qira'ah dari Utsman bin 'Affan, Ali ibn Abi Thalib. Yang meriwayatkan qira'ahnya adalah putranya sendiri Abu Harb dan Yahya bin Ya'mur. Para ahli sejarah menyimpulkan bahwa Abul Aswad adalah orang pertama yang menyusun ilmu Nahwu setelah mendapat rekomendasi dari Ali r.a. Abul Aswad meninggal di Basrah pada tahun 69 $\mathrm{H}$, pada usia delapan puluh lima tahun ketika terjadi wabah pes. Namun adapula yang mengatakan bahwa ia wafat sebelum terjadinya wabah pes.

\section{Abdurrahman bin Hurmuz}

Nama lengkapnya Abu Dawud Abdurrahman bin Hurmuz bin Abi Sa'ad al-Madini al-A'raj, hamba Ibnu Rabi'ah bin al-Harits bin Abdul Muthalib. Abdullah bin al-Hai'ah meriwayatkan dari Abi Nadhr bahwa Abdurahman bin Hurmuz adalah orang pertama yang menyusun bahasa Arab dan dialah orang pertama yang paling tahu ilmu nahwu dan seorang keturunan Quraisy. Abdurrahman bin Hurmuz termasuk ahli qari dan juga termasuk rijalul hadits. Ini diriwayatkan dari Abdullah bin Bahinah, Abu Hurairah dan Abdurrahman bin Abdul Qari. Ia termasuk ahli fiqih dan berbeda pendapat dengan Malik bin Anas, ilmu yang diperdebatkan adalah mengenai ushul al-din. Abdurrahman bin Hurmuz

Islam, Jilid IV (Cet. III, Jakarta: Ikhtiar Baru Van Houve, 1994), h. 2 
pindah ke Iskandariah, dan bermukim di sana sampai wafat pada tahun $117 \mathrm{H}$. Karakteristik periode ini:

a. Tergabung dalam profesi Qori'. Para ulama Basrah secara menyeluruh sebagai Qari AlQur'an, yang mempelajari hukumhukumnya, yang haus akan bacaan alQur'an dan juga sebagai para perawi hadits.

b. Memberi perhatian khusus terhadap lahn dalam kalam Arab, dan dalam al-Qur'an dan menentang fenomena terlarang ini.

c. Mushaf-mushaf diberi titik dengan i'rab yang dimulai oleh Abul Aswad Ad-Duali yang mendapat nasihat dari Ziyad ibn Abihi, kemudian diikuti oleh murid-murid setelahnya, sebagai penentangan terhadap lahn dalam al-Qur'an.

d. Awal penyusunan ilmu nahwu mendapat petunjuk dari Imam Ali r.a yang diawali oleh Abul Aswad dan diikuti oleh muridmuridnya.

e. Tidak terdapat peninggalan berupa tulisan tentang generasi ini kecuali riwayat yang diklaim oleh Ibn Nadiim dan Qifthi. ${ }^{21}$

\section{GENERASI KEDUA}

1. Yahya bin Ya'mur Al-Udwan Al-Laitsi

Abu Sulaiman Yahya bin Ya'mur bin Wasyqah bin Auf bin Bakr bin Yaskur bin Udwan ibn Qais bin Ilan bin Mudhar. Dia dari golongan Bani Laits. Ibnu Ya'mur termasuk orang yang belajar dari Abul Aswad mengenai memberi titik mushaf dengan titik i'rab.

\section{Maimun Al-Aqran}

Abu Abdullah Maimun Al-Aqran, dipanggil juga Maimun bin al-Aqran. Belajar Nahwu dari Abul Aswad. Abu Ubaidah berkata:"Orang yang pertama kali menyusun ilmu nahwu adalah Abul Aswad Ad-Duali, kemudian Maimun al-Aqran, kemudian Anbasah al-Fail, dan Abdullah bin Abi Ishaq".

\section{Anbasah Al-Fil}

Anbasah bin Mu'dan al-Misani alMahri. Orangtuanya (Mu'dan) adalah dari
Misan, kemudian berpindah ke Basrah dan bermukim di sana.

\section{Nashr bin Ashim Al-Laitsi}

Nama lengkapnya Nashr bin Ashim bin Umar bin Khalid bin Hazm bin As'ad bin Wadi'ah bin Malik bin Qais bin Amir bin Laits bin Bakr bin Abdi Manah bin Ali bin Kinanah. Dalam hal keturunan ia bertemu dengan Abul Aswad Ad-Duali dari Bakr bin Abdi Mannah. Ia seorang yang faqih dan berpengetahuan di bidang bahasa Arab, termasuk dari tabiin terdahulu: Ia juga termasuk ahli Qira yang fasih, dalam hal al-Qur'an dan nahwu ia menyandarkan pada Abul Aswad. Nashr belajar Nahwu juga dari Yahya bin Ya'mur. Dari Abu Umar bin Ula dikatakan bahwa ia memiliki sebuah buku dalam bahasa Arab. Ia meninggal pada tahun $89 \mathrm{H}$. Karakteristik periode ini:

a. Tergabung dalam profesi Ahli Qira dan Ahli Hadits.

b. Memiliki perhatia pada realitas lahn dalam kalam Arab dan al-Qur'an, juga dalam pembicaraan para pemimpin seperti al-Hajjaj bin Yusuf al-Tsaqfi dan pemimpin lainnya.

c. Ada kesepakatan dalam memberi titik mushaf dengan titik i'rab.

d. Memberi titik mushaf dengan titik dan harakat atas nasihat dari Hajjaj bin Yusuf al-Tsaqfi.

e. Terdapat tambahan atas penyusunan ilmu Nahwu.

e. Belum terdapat peninggalan berupa tulisan. ${ }^{22}$

\section{GENERASI KETIGA}

1. Abdullah bin Abu Ishak

Ia belajar al-Qur'an dari Yahya bin Ya'mur dan Nashr bin Ashim dan belajar nahwu dari Maimun al-Aqran. Dikatakan bahwa ia belajar nahwu dari Yahya bin Ya'mur. Hatim meriwayatkan dari Dawud bin Zibriqah dari Qatadah bin Da'amah ad-

${ }^{22}$ ibid 
Daus, ia berkata:"Orang pertama yang menyusun nahwu setelah Abul Aswad adalah Yahya bin Ya'mur, dan belajar darinya Abdullah bin Abu Ishak.

\section{Abu Umar bin Ula}

Al-Riyasy meriwayatkan dari alAshma'i, ia berkata:"Saya bertanya pada Abu Umar:"Siapa namamu?" Ia menjawab:"Nama saya Abu Umar". Abu Ubaidah berkata:"Abu Umar adalah manusia yang paling tahu di bidang sastra, bahasa Arab, al-Qur'an dan puisi". AlA'shami berkata:"Saya bertanya pada Abu Umar seribu pertanyaan, maka dia pun memberi jawaban dengan seribu hujjah". Ia meninggal di Kufah pada tahun $154 \mathrm{H}$, ada pula yang mengatakan $159 \mathrm{H}$.

\section{Isa bin Amr al-Tsaqfi}

Ia belajar nahwu dari Abdullah bin Ishak dan Abu Umar al-Ula. Kemudian, Al-Khalil bin Ahmad, Yunus bin Habib dan Sibawaih.belajar darinya. Karakteristik periode ini:

a. Dimulainya derivasi qiya $>s$, dan implementasinya atas pembacaan alQur'an dan puisi Arab.

b. Dimulainya $t a^{\prime} l i>l$ kaidah nahwu dan $t a^{\prime} w i>l$ terhadap hal yang menyalahi kaidah.

c. Munculnya berbagai pendapat seperti terdapatnya perbedaan pendapat antara Abu Umar al-Ula dan Abdullah bin Abu Ishak, dan antara Abu Umar al-Ula dan Isa bin Amr.

d. Munculnya pendapat nahwu yang bersifat individual, dan pembacaan alQur'an yang berbeda dari ulama Jumhur.

e. Tidak terdapat peninggalan berupa tulisan kecuali yang diriwayatkan dari al-Jami' dan al-Kamil karya Isa ibn Amr. $^{23}$

\section{GENERASI KEEMPAT}

\section{Al-Akhfas al-Akbar}

Ia berpendapat (طاءر الخفوف) yang diriwayatkan oleh Ibn Duraid: tidak ada salah seorang dari sahabat kita yang menyebutkan kata tersebut.

2. Al-Khalil bin Ahmad

Karya-karya al-Khalil dalam bahasa:

a. Kitab Ma 'anil-Huruf

b. Kitab an-Naqth wat-Tasykil

c. Kitab al-Jamal

d. Kitab asy-Syawahid

e. Kitab al-'Ain

Dalam ilmu Arud:

a. Kitab al-Arudh

b. Kitab al-Farsy wal-Mitsal

Al-Khalil meninggal pada tahun $170 \mathrm{H}$.

3. Yunus bin Habib

Salah satu pendapatnya berkaitan dengan Nahwu bahwa tashgir untuk kata قبقيّل adalah sementara Khalil dan Sibawaih berpendapat قبئيل

\section{GENERASI KELIMA}

\section{Sibawaih}

Karya Sibawaih adalah Kitab Sibawaih. Tidak ada keterangan tentang kapan penyusunan kitab tersebut. Dalam menyusun kitab ini, Sibawaih banyak mengambil manfaat dari ilmu yang dimiliki Khalil. Sibawaih meriwayatkan dalam kitabnya tentang para ahli nahwu, meskipun tidak jelas apakah dia bertemu mereka atau belajar dari mereka secara lisan. Mereka itu adalah Abu Umar bin Ula, Abdullah bin Abi Ishak, al-Ru'as dan para ahli Kufah. ${ }^{25}$

Ada dua sumber yang dipakai Sibawaih sebagai argumentasi dalam menguatkan pendapatnya mengenai sebuah persoalan tatabahasa, yaitu puisi Arab dan hadits Nabi Muhammad SAW. Dalam kitabnya, Sibawaih menggunakan kurang lebih seribu lima ratus bait puisi. Banyak dari puisi-puisi tersebut tidak disebutkan sumbernya, entah karena penciptanya sudah

\footnotetext{
${ }^{24}$ Ibid

${ }^{25}$ Sibawaih melengkapi ilmu nahwu yang diwarisi dari gurunya al-Khalil secara mendetail. Selengkapnya lihat Ibn Khaldun, Muqaddimah, diterjemahkan oleh ahmadie Thoha dengan judul Muqaddimah Ibn Khaldun, Cet. VIII (Jakarta: Pustaka Firdaus, 2009), h. 777
} 
meninggal atau memang tidak diketahui. Karena takut salah, adakalanya Sibawaih mencantumkan dua bahkan lebih sumber untuk satu puisi. Puisi-puisi itu ada yang dinyatakan bersumber dari gurunya atau dari pendengarannya sendiri. Syaikh Muhammad al-Thanthawy menyatakan adanya tiga puluh satu puisi tanpa sumber yang jelas, sedangkan Syaikh Abdul Qadir al-Baghdady menyebut angka lima puluh. Berikut ini kami sampaikan pendapat beberapa ulama terkait puisi-puisi tanpa sumber ini. ${ }^{26}$

\section{2. 'Uqaibah bin Hubairah al-Asady}

$$
\text { مُعَاوِ }
$$

Sibawaih menyatakan bahwa kata الحديدال mansub karena ma‘thuf kepada kata الجبال Kata الجبال اitu sendiri mansub, sedangkan ba' adalah zaidah. 'Uqaibah menyatakan bahwa Qutaibah menyalahkan pendapat Sibawaih di atas dan kata الحديدا harus dibaca majrur sebagaimana umumnya qasidah puisi Arab. Al-Mubarrad juga mengikuti pendapat Qutaibah ini.

\section{Nahsyal bin Hurry}

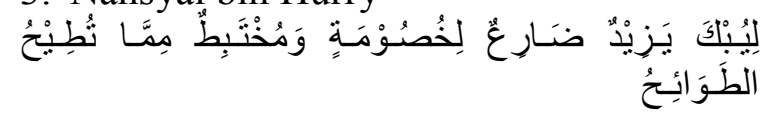

Sibawaih menyatakan bahwa kata ضسارع marfu' karena merupakan naibul fa'il yang sudah diketahui dari kata ليبك. Nahsyal menyampaikan pendapat al-Ushmu'i yang menyangkal pendapat ini, karena tidak ada na'ibul fa'il dari fi'l mahzhuf. Kata يزيد harus tetap mansub, sedangkan kata ضـار ع adalah fa'il.

\section{Al-Akhthal}

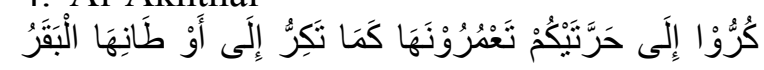

Sibawaih menggunakan bentuk di atas untuk orang kedua ketika dia menggunakan

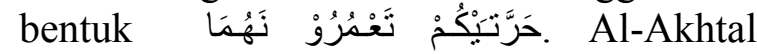
menyampaikan kritik Syaikh Muhammad al-Thanthawy mengenai bait syair di atas. Bentuk di atas seharusnya digunakan untuk orang ketiga, bukan untuk orang kedua. Bagi al-Thantawy, Sibawaih seharusnya

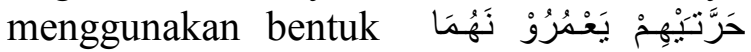
Dalam menyusun kitabnya, Sibawaih telah menyusun materi-materi tatabahasa Arab dengan sistematis. Dari satu bagian ke bagian lain terdapat jalinan yang padu sehingga memudahkan para pembaca. Pada akhir bagian selalu ada epilog yang menyambungkan dengan bagian sesudahnya. Tidak ada pemisahan pembahasan dalam setiap bagian. Pembahasan dalam kitab Sibawaih berdasar pada contoh-contoh asli bahasa Arab agar dapat langsung menentukan antara bentuk kalimat yang benar dan yang salah. Kitab itu sendiri terdiri atas 820 bab. Penyusunan bab-bab itu berbeda dengan umumnya penulis dalam beberapa hal, yaitu:

a. Urutan yang dipakai bukan pembahasan mengenai marfu'at, kemudian manshubat, dan seterusnya, tetapi pembahasan dimulai dengan pembahasan fa'il yang bersambung dengan pembahasan maf 'ul, atau pembahasan mubtada' yang disambung dengan pembahasan mengenai khabar.

b. Mendahulukan pembahasan yang seharusnya di akhir dan mengakhirkan pembahasan yang seharusnya di awal, misalnya mendahulukan pembahasan musnad ilaih dan baru disambung dengan pembahasan musnad.

c. Membahas dari masalah yang umum ke yang khusus, misalnya membahas tasghir secara umum, kemudian dilanjutkan dengan pembahasan mengenai berbagai macam bentuk tasghir.

d. Beberapa pembahasan dilakukan sampai selesai, misalnya pembahasan mengenai fa'il dimulai dengan fa'il tanpa maf'ul, fa'il dengan satu maf'ul, dan diakhiri fa'il dengan dua maf'ul. Pada masa sekarang, pembahasan ini biasanya diletakkan pada pembahasan mengenai fi'l muta'adi dan lazim. 
e. Kadang-kadang suatu pembahasan berada dalam satu bab, sedangkan pembahasan yang lain berada pada bab yang lain agar mendapatkan kecocokan.

f. Karena belum ada istilah-istilah baku untuk tatabahasa Arab, Sibawaih masih menggunakan kata-kata yang panjang untuk membuat judul suatu bab, misalnya untuk inna wa akhwatuha dia menggunakan kata-kata 'bab mengenai lima partikel yang berfungsi seperti fi'‘ terkait dengan kata-kata sesudahnya'. ${ }^{27}$

Kitab Sibawaih banyak mendapat pujian karena kelengkapannya. Di Basrah, kitab ini adalah kitab pokok ilmu tatabahasa Arab. Akan tetapi, banyak juga orang yang tidak percaya bahwa kitab ini adalah karya Sibawaih sendiri. Mereka mengira Sibawaih mengerjakan kitab ini bersamasama orang lain. Kitab Sibawaih telah mengalami enam kali cetak. Cetakan pertama di Paris pada tahun 1881, disambung dengan cetakan kedua di Calcutta tahun 1887, cetakan ketiga di Jerman tahun 1895, cetakan keempat di Kairo tahun 1898, cetakan kelima di Baghdad, dan cetakan keenam di Kairo tahun 1966.

2. Al-Yazidy

Namanya Yahya bin al-Mubarak bin al-Mughirah al-'Adwy. Nama al-'Adwy disambungkan kepada 'Ady bin 'Abd Manah bin Add bin Thabikhah bin Ilyas bin Mudhar bin Nazar bin Ma'd bin Adnan. Kabilah ini kabilah yang besar dan terkenal. Kakeknya, al-Mughirah, adalah tuan seorang perempuan dari Bani 'Ady. Nama al-Yazidy didapatkannya karena dia pertama kali mengajar anak-anak Yazid bin Manshur bin 'Abdullah bin Yazid alHamiry yang juga paman al-Mahdy. Nama al-Yazidy ini kemudian diberikan kepada keturunannya. Al-Yazidy tinggal di Basrah. Dia belajar ilmu qira'ah kepada 'Amr bin al-'Ala dan nachw serta 'arudh kepada Khalil bin Ahmad. Kemudian dia

\footnotetext{
${ }^{27}$ ibid
}

menggantikan 'Amr mengajar sambil berguru kepada 'Abdullah bin Ishaq dan Yunus bin Habib. Setelah itu, al-Yazidy mengajar anak-anak Yazid bin Manshur. Yazid kemudian menghubungkan al-Yazidy dengan khalifah Harun ar-Rasyid dan khalifah memerintahkan al-Yazidy untuk mengajar al-Ma'mun, sedangkan al-Kisa'iy mengajar al-Amin. Al-Yazidy dan alKisa'iy sering terlibat dalam perdebatan, tetapi al-Yazidy lebih sering menang. Beberapa kitab yang disusun oleh al-Yazidy di antaranya adalah: an-Nawadir filLughah, al-Maqshur wal-Mamdud, Mukhtashar fin-Nachw, an-Naqth watTasykil. Dia meninggal pada tahun $202 \mathrm{H}$ di Khurasan. Sibawaih dan al-Yazidy adalah dua ulama yang berperan pada periode kelima. Pada masa ini, ilmu tatabahasa Arab memiliki beberapa kelebihan dibandingkan periode-periode sebelumnya, yaitu:

a. Penyempurnaan konsep ilmu tatabahasa Arab

b. Kitab-kitab yang disusun

c. Adanya diskusi-diskusi. ${ }^{28}$

\section{GENERASI KEENAM}

1. Al-Akhfasy ${ }^{29}$ al-Awsath

\footnotetext{
${ }^{28}$ ibid

${ }^{29} \mathrm{Al}$-Akhfasy adalah sebutan yang diberikan karena matanya kecil dan penglihatannya lemah. Abu alHasan Sa'id bin Mas'adah dikenal sebagai "alAkhfasy al-Shaghir" sedangkan 'Abdul Hamid bin "Abdurrahman dikenal sebagai "al-Akhfasy alKabir”. Al-Akhfasy dilahirkan di Balkh, sedangkan riwayat yang lain mengatakan di Khawarizm. Dia datang ke Basrah untuk menuntut ilmu kepada Sibawaih. Al-Akhfasy dikenal sebagai pengikut $\mathrm{Mu}$ 'tazilah, walaupun ada yang mengatakan bahwa dia pengikut Qadariyyah-Murji'ah aliran Abu Syimr. Al-Akhfasy adalah teman dekat Sibawaih ketika dia terusir dari Baghdad karena kalah berdebat dengan al-Kisa'iy. Al-Akhfasy adalah sumber utama konsep tatabahasa Arab yang disusun Sibawaih karena tidak ada satu konsep pun dari tatabahasa Sibawaih yang tidak dibaca al-Akhfasy. Al-Kisa'iy sendiri secara rahasia meminta al-Akhfasy untuk membacakan kitab Sibawaih dan memberikan hadiah lima puluh dinar. Lihat Abd al-'Al Salim Mukrim, Alquran al-
} 
Nama lengkapnya adalah Abu alHasan Sa'id bin Mas'adah, hamba Bani Mujasyi' bin Darim bin Malik bin Hanzhalah bin Zaid Manah bin Tamim. Sebenarnya, al-Akhfasy adalah penggagas utama mazhab Kufah. Al-Kisa'iy secara khusus menempatkan al-Akhfasy di sampingnya dengan segala kemuliaan. AlAkhfasy sendiri adalah guru putra-putra alKisa'iy. Banyaknya kemuliaan yang diterima al-Akhfasy di Baghdad mengakibatkan lunturnya semangat Basrah dan mendekatkan dia ke mazhab Kufah. AlAkhfasy mulai membantah pendapat gurunya, Sibawaih serta al-Khalil, dan membantu para ulama aliran Kufah dalam menyusun mazhab mereka. Al-Akhfasy menunjukkan kepada para ulama Kufah beberapa pendapat berbeda mengenai tatabahasa yang kemudian mereka ikuti. Beberapa pendapat yang diikuti di antaranya:

1. Min jarr za'idah dalam kalimat aktif, misalnya

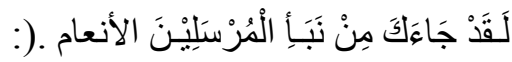

2. Pemberlakuan ketentuan inna ketika

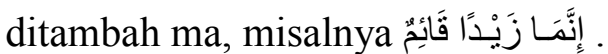

3. Penggunaan tanwin pada kata نَالِنَ

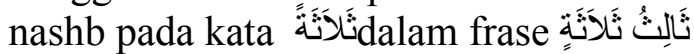

4. Penggunaan lam al-ibtida'iyyah pada ni'ma dan bi'sa, misalnya إِنَّ مُحَمَدًا لَنَعْمَ الرَّجُلِ

5. Marfu' pada zharf muqaddam, misalnya

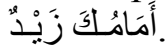

Al-Akhfasy dikenal sangat cerdas. Para ulama mengakuinya karena banyak sekali kitab yang dia susun, yaitu alAwsa $>t\}$, al-Maqa $>y i s$, al-Isytiqa $>q$, alMasa $>$ 'il, Waqf al-Tama $>m$, al-As\}wa>t, Tafsi $>r$ Ma 'a>ni al-Qur'a>n al-Kari $>m$, al-Arba'ah, al-'Aru>d, al-Qawa>fi, Ma'a>ni al-Syi'r, al-Mulu>k, dan alGanam; Alwa $>$ nuha $>$ wa 'Ila $>$ juha $>$. Ada beberapa pendapat mengenai tahun

Karim wa Atsruh fi al-Dirasat al-Nahwiyah, Cet. I (Mesir: Dar al-Ma’arif, 1968), h. 89 wafatnya al-Akhfasy, yaitu tahun $211 \mathrm{H}$, $215 \mathrm{H}, 221 \mathrm{H}$, dan $225 \mathrm{H}^{30}$

\section{Qatrab}

Namanya ialah Abu 'Ali Muhammad bin al-Mustanir, hamba Salm bin Ziyad. Dia lahir dan besar di Basrah kemudian belajar tatabahasa kepada 'Isa bin 'Umar, Yunus bin Habib, dan Sibawaih. Nama Qat\}rab diberikan oleh Sibawaih karena dia sering menunggui Sibawaih di depan pintu rumahnya pada malam hari (قطرب ليل), sehingga ketika Sibawaih bangun pagi, Qatrab sudah berada di depan rumah. Qatrab sendiri beraliran Mu'atzilahNizhamiyyah. Salah seorang panglima perang khalifah Harun ar-Rasyid, yaitu Abu Dalf al-'Ajliy memperkenalkannya kepada khalifah sehingga dia diminta mengajar alAmin, al-Ma'mun, dan putra-putra Abu Dalf. Setelah meninggal, pengajaran dilanjutkan oleh putranya, al-Husain. Qatrab memiliki beberapa pendapat yang berbeda dengan ulama-ulama sebelumnya, baik itu al-Khalil, Sibawaih, maupun alAkhfasy. Beberapa pendapat Qatrab ialah misalnya:

a. Tanda baca pada i'rab berupa raf', nashb, jarr, dan jazm, pada hakekatnya adalah tanda baca berupa dhammah, fathah, kashrah, dan sukun.

b. Al-Khalil dan Sibawaih menyatakan bahwa i'rab untuk mutsanna dan jam' mudzakkar salim itu muqaddarah pada alif, waw, dan ya', sedangkan Qatrab berpendapat bahwa i'rab-nya muqaddarah pada huruf sebelum alif, waw, dan ya'.

c. Sibawaih berpendapat bahwa i'rab untuk al-asma' al-khamsah itu muqaddarah pada waw, alif dan ya', sedangkan Qatrab berpendapat bahwa i'rab-nya itu muqaddarah pada huruf sebelum waw, alif dan ya'. 31

Di samping perbedaan di atas, Qatrab juga menyusun banyak kitab dalam 
berbagai bidang ilmu, seperti al-Qur'an, alHadits, dan bahasa. Di antara kitab-kitab itu adalah: Ma'ani al-Qur'an, I'rab al-Qur'an, ar-Radd 'ala al-Mulhidin fi Mutasyabih alQur'an, Gharibil-Atsar, al-'Ilal fin-Nahw, al-Mutsallats fin-Nachw, al-Adhdad, alHamz, Fi'1 wa Af'al, al-Qawafi, ash-Shifat, al-Ashwat, an-Nawadir, al-Azminah, alFarq, Chalaqul-Insan, dan Khuluqul-Furs. Banyaknya kitab ini membuktikan kecerdasan Qatrab sebagaimana diakui oleh para ulama. Qatrab meninggal pada tahun 206 H. Al-Akhfasy dan Qatrab adalah dua ulama dari masa periode keenam. ${ }^{32}$ Jadi pada periode ini, ada beberapa kemajuan dan dicapai, seperti; pemikiran yang tajam, jelas, dan luas, akomodatif terhadap budaya secara umum, banyaknya karangan, kepercayaan diri untuk menyusun pendapat sendiri, dekat dengan pemerintah dan kalangan elit politik dan pengembangan keilmuwan.

\section{GENERASI KETUJUH}

\section{Al-Jurmy}

Namanya Abu 'Umar Shalih bin Ishaq al-Bajly, hamba Bajilah bin Anmar bin Irasy bin al-Ghauts. Nama al-Jurmy dihubungkan dengan Jarm bin Rabban bin 'Imran bin Ilhaf bin Qadha'ah karena dia dihadiahkan kepada Jarm. Jarm adalah salah satu kabilah Yaman yang terkenal. Al-Jurmy lahir dan besar di Basrah kemudian belajar tatabahasa kepada al-Akhfasy al-Awsath dan Yunus bin Habib. Dia juga belajar ilmu bahasa dari Abu 'Ubaidah, Abu Zaid alAnshary, Ushmu'i, dan ulama-ulama lain yang semasa. Kemudian al-Jurmy pergi ke Baghdad dan mengalahkan alFarra' dalam sebuah debat. Dia terkenal suka berbicara keras dalam setiap perdebatan sehingga mendapat gelar "alKalb (anjing)". Al-Jurmy juga terkenal cerdas dan ahli di bidang hadits. Beberapa kitab yang telah disusun di

\footnotetext{
${ }^{32} \mathrm{ibid}$
}

antaranya: al-Farh, at-Tatsniyah walJam', Tafsir Gharib Sibawaih, Mukhtashar Nahwil-Muta'allimin, alAbniyah, at-Tashrif, al-Arudh, alQawafi, dan as-Siyar. Al-Jurmy wafat pada tahun $225 \mathrm{H}$.

\section{At-Tauzy}

Dia bernama Muhammad 'Abdullah bin Muhammad bin Harun. Nama at-Tauzy dihubungkan dengan negeri Tauz di Persia. Dia berguru kepada al-Usmu'i, Abu 'Ubaidah, Abu 'Umar al-Jurmy, Abu Zaid al-Anshary, dan al-Akhfasy. At-Tauzy adalah salah seorang pegawai khalifah al-Watsiq dan dia menikah dengan ibu seorang ahli tatabahasa bernama Abu Dzakwan al-Qasim bin Isma'il. At-Tauzy menyusun beberapa kitab, di antaranya: al-Amtsal, alAdhdad, an-Nawadir, Fa'altu wa Af'altu, dan al-Khail. Banyak perbedaan pendapat mengenai tahun waftnya atTauzy, yaitu tahun $230 \mathrm{H}, 233 \mathrm{H}$, dan $238 \mathrm{H}$.

3. Al-Maziny.

Dia bernama Abu 'Utsman Bakr bin Muhammad bin 'Utsman. Nama al-Maziny dihubungkan dengan Bani Mazin bin Syaiban bin Dzahl bin Tsa'labah bin 'Ukabah bin Sha'b bin 'Ali bin Bakr bin Wail. Dia adalah hamba Bani Sadus yang dihadiahkan kepada Bani Mazin. Al-Maziny adalah ahli tatabahasa dan qira'ah. Pada masa al-Watsiq di Samarra', al-Maziny berada di sampingnya untuk membacakan kitab Sibawaih atas permintaan al-Mubarrad. Al-Maziny mendapatkan belanja sebanyak seratus dinar setiap bulan dari al-Watsiq. AlMaziny wafat di Basrah pada tahun $249 \mathrm{H}^{33}$ Dari segi ideologi, al-Maziny adalah pengikut aliran Murji'ah. Al-Maziny dikenal sebagai ulama yang sangat anti terhadap analogi (qiyas) dalam merumuskan kaidah-kaidah tatabahasa dan qira'ah. Banyak kitab yang telah disusun oleh al-Maziny, di antaranya:

\footnotetext{
${ }^{33}$ ibid
} 
'Ulumul-Qur'an, 'Ilalin-Nachw, Tafasir Kitab Sibawaih, Lachnul-'Ammah, al'Alif wal-Lam, al-'Arudh, al-Qawafy, dan ad-Dibaj. Dia tidak mau menyusun sebuah kitab tatabahasa dengan menyatakan bahwa siapa saja yang menyusun kitab tatabahasa setelah Sibawaih, maka dia akan merasa malu. Akan tetapi, al-Maziny memiliki pendapat sendiri, di antaranya:

a. Alif mutsanna, waw jam', dan ya' al-mukhathabah pada fi' 1 , misalnya

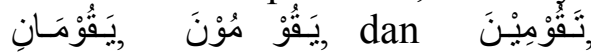
bukanlah fa'il, tetapi tanda tatsniyah, jam', dan ta'nits. Adapun fa'il adalah damir mustathir.

b. Alif, waw, dan ya' pada mutsanna' dan jam' mudzakkar salim,

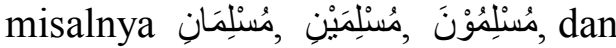
مُسنْلِيْينَ , bukanlah tanda i'rab, tetapi tanda mutsanna' dan jam“ mudzakkar salim.

c. Jam' mu'annats salim wajib mabni fathah jika didahului la nafiyah lil-

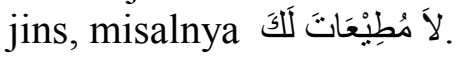

d. Al-Khalil menyatakan bahwa 'ain fi'll dalam kata seperti إِنَنَحْيَىَى 'itu dibuang karena ada pertemuan dua sukun, sedangkan al-Maziny menyatakan bahwa 'ain fi'l itu dibuang karena sebagai takhfif karena banyak digunakan.

e. Sibawaih menyatakan bolehnya qiyas pada ism tafdhil dari fi'l

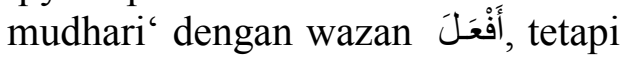
al-Maziny menyatakan tidak boleh sehingga tidak ambigu antara fi' 1 madhi dan ism tafdhil.

\section{Abu Chatim as-Sijistany}

Namanya Sahl bin Muhammad bin 'Utsman bin al-Qasim bin Yazid alJuzmy al-Sijistany. As-Sijistany adalah nama musim yang terkenal di Basrah. AlSijistany tinggal di Basrah dan menjadi mahaguru di bidang al-Qur'an, bahasa, dan sastra. Dia berguru kepada alAkhfasy di samping banyak menyampaikan pendapat dari Abu Zaid al-Anshary, Abu 'Ubaidah, al-Ushmu'i, 'Umar bin Karkarah, dan Ruh bin 'Ubadah. Ulama semasanya juga banyak mengambil pendapat dari dia, seperti Abu Bakr Muhammad bin Duraid dan al-Mubarrad. As-Sijistany terkenal karena rutin berderma sebanyak satu dinar setiap hari dan meng-khatam-kan al-Qur'an setiap minggu. Dalam bidang fiqh, as-Sijistany sangat fanatik terhadap ahlul-hadits. Dia tidak pernah tinggal di Baghdad. As-Sijistany banyak meninggalkan kitab yang berharga, baik di bidang ilmu al-Qur'an, tatabahasa, dan lain-lain, seperti: I'rabul-Qur'an, alQira'at, al-Maqathi' wal-Mabadi', Ikhtilaful-Mashahif, al-Mukhtashar finNachw, Lachnul-'Ammah, al-Maqshur wal-Mamdud, al-Mudzakkar walMu'annats, al-Isyba', al-Adhdad, alHaja', al-Fashahah, asy-Syajaru wanNabat, an-Nakhlah, al-Karam, al-'Usybu wal-Baql, al-Wuchusy, al-Chasyarat, azZar', al-Jarad, Chuluqul-Insan, al-Qasy was-Siham wan-Nibal, as-Suyuf warRimach, al-Laba' wal-Laban wal-Chalib, al-Khashb wal-Qachth, an-Nachl wal'Asal, asy-Syita' wash-Shaif, al-Ibil, alCharr wal-Bard wasy-Syams wal-Qamar wal-Lail wan-Nahar, al-Farq bainalAdamiyyin wa baina kulli dzi Ruch, dan Asyuq ilal-Wathan. Abu Chatim asSijistany wafat pada bulan Rajab tahun $255 \mathrm{H}^{34}$

\section{Al-Riyasyy}

Dia bernama Abu al-Fadhl 'Abbas bin al-Farj, hamba dari Muhammad bin Sulaiman bin 'Ali al-Hasyimy. ArRiyasyy dihubungkan dengan seseorang dari Jadzam yang bernama Riyasy yang menjadi tuan al-Farj, ayah 'Abbas, kemudian dia menjual al-Farj kepada alHasyimy. Akan tetapi, nama 'Abbas tetap dihubungkan dengan tuan

\footnotetext{
${ }^{34}$ ibid
} 
sebelumnya, yaitu Riyasy. Ar-Riyasyy adalah ahli di bidang bahasa dan puisi. Dia banyak meriwayatkan dari Ushmu'i, Abu 'Ubadah dan lain-lain. Ulamaulama yang lain, seperti al-Mubarrad, Ibnu Duraid, Ibrahim al-Charby, dan Ibnu Abid-Dunya, juga mengambil pendapatnya. Ar-Riyasyy juga dikenal sebagai orang yang zuhud, banyak mempergunakan waktunya untuk ilmu, dan seorang penopang mazhab Basrah. Ar-Riyasyy tewas terbunuh di daerah Zanj di Basrah pada tahun $257 \mathrm{H}$ pada masa pemerintahan khalifah alMutawakkil. Khalifah menyerbu Zanj karena menjadi markas perlawanan kaum Alawiyyin yang dipimpin oleh 'Ali bin Muhammad bin 'Isa. ArRiyasyy adalah ulama terakhir periode ketujuh. Periode ini memiliki beberapa kelebihan, di antaranya:

a. Ada pemisahan antara nahw dan tashrif.

b. Mengarah pada kemudahan dalam merumuskan kaidah tatabahasa.

c. Banyak ulama yang menggunakan teknik taqdir (perkiraan).

d. Pemendekan pada teknik simak dan qiyas (analogi).

e. Tidak menggunakan contoh-contoh di luar bahasa Arab.

f. Banyak perdebatan antar para ulama.

g. Banyak teknik yang tidak fungsional dalam sharf.

h. Bersandar pada pendapat sendiri tanpa mengikuti pendapat ulama sebelumnya.

i. Banyak karangan dalam berbagai bidang ilmu

j. Banyak perumusan menggunakan informasi dari orang Arab. ${ }^{35}$

\section{GENERASI KEDELAPAN}

\section{Al-Mubarrad}

Dia bernama Abu al-'Abbas Muhammad bin Yazid bin 'Abdul-Akbar bin 'Umair bin Hasan bin Salim bin Sa'd bin 'Abdullah bin Yazid bin Malik bin alCharits bin 'Amir bin 'Abdullah bin Bilal bin 'Auf bin Aslam bin Achjan bin Ka'b bin al-Charits bin $\mathrm{Ka}{ }^{\prime} \mathrm{b}$ bin 'Abdullah bin Malik bin Nashr bin al-Azd bin al-Ghauts. Nama al-Mubarrad diberikan oleh alMaziny kepada Muhammad bin Mazid dia menyusun kitab "al-Alif wal-Lam". Dia berguru pada al-Jurmy, al-Maziny, dan asSijistany. Al-Mubarrad terkenal kikir karena menganggap bahwa kaya itu disebabkan oleh banyak menyimpan sedangkan miskin itu oleh banyak memberi. Sebagaimana al-Maziny, al-Mubarrad memprioritaskan perumusan kaidah dengan teknik mendengar langsung (sama 'i). Hal ini berbeda dengan Sibawaih. Misalnya dalam hal taskin pada fi'l mudhari' pada puisi:

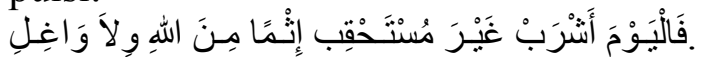

Sibawaih memperbolehkan taskin pada kata أَثَرَبْبُ, sedangkan menurut alفَالْيَوْمَ Mubarrad, bacaan yang benar adalah انَرَبْ sebagai ganti dari dhamir raf' dalam kata

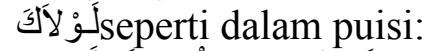

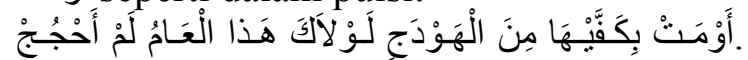
Menurut al-Mubarrad, bacaan seperti ini salah karena dhamir raf' di atas tidak bisa

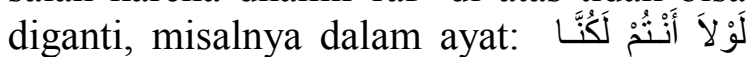

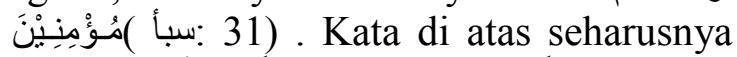

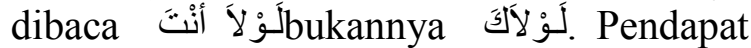
yang lain adalah tasghir dari kata إِِْرَاهِيْمِ dan إِسنمَاعِيْلِ Menurut Sibawaih, kedua kata di atas menjadi سُعَنْعِنْلِ Adapun menurut al-Mubarrad, kedua kata itu menjadi أَسَيْيْيَع karena alif pada kedua kata di atas adalah asli. Pada masa khalifah al-Mutawakkil, al-Mubarrad pernah dimintai fatwa terkait dengan kata

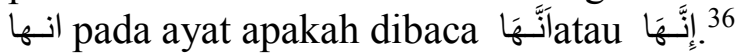

Permintaan ini terkait dengan perbedaan pendapat antara khalifah dengan al-Fath bin Khaqan. Khalifah dan umumnya ulama membaca dengan آنَّهَ . Al-Mubarrad menganggap bacaan itu salah dan 
menyatakan yang benar adalah إنََّّهَا. Akan tetapi, al-Mubarrad tidak berani menyatakan hal ini di depan khalifah dan hanya menyembunyikan pendapatnya.

Al-Mubarrad banyak menyusun kitab yang penting, di antaranya: Nasab 'Adnan wa Qachthan, I'rabul-Qur'an, alIttifaq wal-Ikhtilaf minal-Qur'anil-Majid, al-Fadhil, al-Kamil, al-Muqtadhab, alIsytiqaq, at-Tashrif, al-Madkhal liSibawaih, Syarch Syawahidul-Kitab, Ma'na Kitab lil-Akhfasy, ar-Radd 'ala Sibawaih, Dharuratusy-Syi'r, Generasi NuchatilBashriyyin, al-Maqshur wal-Mamdud, dan al-Qawafy. Dia meninggal pada hari Senin tanggal 28 Dzulhijjah $286 \mathrm{H}$ dan dimakamkan di sebuah rumah depan pintu masuk kota yang dibelinya. Al-Mubarrad adalah satu-satunya ulama peride kedelapan dan periode ini memiki kelebihan dibandingkan periode sebelumnya, di antaranya:

a. Menyusun sebuah kitab berdasarkan pendapat sendiri.

b. Menggunakan pendapat ulama terdahulu dalam beberapa pembahasan.

c. Pembahasan dalam bermacam-macam bidang ilmu.

d. Penggunaan metode-metode baru dalam tatabahasa, seperti qiyas, sima', ta'lil, 'awamil, dan ma'lumat.

e. Banyaknya diskusi

\section{KESIMPULAN}

Aliran Basrah berkembang pesat hingga terkenal di kalangan para ulama nahwu, disebabkan semangat dan motivasi orang dalam mempelajari ilmu nahwu yang langsung diajar oleh penyusun kitab nahwu pertama kali, Abu Aswad ad-Dhuali. Ketika itu penduduk asli Basrah telah bercampur dengan non pribumi yang hidup layaknya seperti penduduk asli. Bahasa arab merupakan bahasa resmi negara pada waktu itu, namun karena adanya percampuran dengan non pribumi dalam negeri Arab otomatis berimplikasi kepada terjadinya kesalahan berbahasa berupa lahn yang tidak sesuai dengan kaidah dan uslub bahasa arab.

Sibawaih merupakan salah satu produk aliran Basrah, yang telah mengarang buku nahwu yang berjudul "alKitab". Di antara ciri khas aliran Basrah selalu berpegang pada pendapat jumhur bahasa bila terdapat khilaf. Jika terdapat yang menyalahi jumhur mereka takwilkan atau menggolongkannya sebagai kelompok yang ganjil (syaz), dan aliran ini selalu menggunakan sama'i dalam memecahkan suatu masalah yang berkaitan dengan gramatikal bahasa arab.

\section{DAFTAR PUSTAKA}

Arsyad, Azhar. Madkhal ila Thuruq Ta'lim al-Lughah al-Arabiyah, cet. I. Makassar: percetakan al-Ahkam, 1998

Dheef, Syauqiy, al-Madaris al-Nahwiyah, Cet. III, Beirut: Da $>$ r al-Ma'a $>$ rif, t.t

Galayainiy. Mushthofa. Ja>mi'al-Duru $>s$ al-'Arabiyah, Juz I, Maktabah 'Ashriyah. 1994

Harun, Abd al-Salam. Kitab Sibawaih, Juz I (Dar al-Jail, t.t)

Ibn Khaldun, Muqaddimah, diterjemahkan oleh ahmadie Thoha dengan judul Muqaddimah Ibn Khaldun, Cet. VIII, Jakarta: Pustaka Firdaus, 2009

al-Mubarak, Mazin. al-Nahw al-Arabiy; al'Illah al-Nahwiyyah, Jilid III, Dar al-Fikr, 1981

Mukrim, Abd al-'Al Salim, Alquran alKarim wa Atsruh fi al-Dirasat alNahwiyah, Cet. I, Mesir: Da>r al-Ma'a>rif, 1968

Mu'minin, Imam Siful, Kamus Ilmu Nahwu dan Sharaf, Cet. II, Jakarta: Amzah, 2009 
Redaksi, Dewan. Ensiklopedia Islam, Jilid I dan IV, (Cet. III, Jakarta: Ikhtiar Baru, Van Houve, 1994

Salim Mubarak, Abd al-'Al, Alquran alKarim wa Atsaruhu fi al-Dirasat alNahwiyah, Cet, I, Mesir: Dar al-Ma'arif, 1968

al-Thahthowiy, Nasy ah al-Lughah, t. t 